\title{
RA?EGA
}

O ESPAÇO GEOGRÁFICO EM ANÁLISE

\section{FRAGILIDADES AMBIENTAIS E VULNERABILIDADE DOS PECUARISTAS FAMILIARES FRENTE À DISPONIBILIDADE HÍDRICA DO ALTO CAMAQUÃ/RS}

\author{
ENVIRONMENTAL FRAGILITIES AND FAMILY LIVESTOCK VULNERABILITY AGAINST THE \\ HYDRICAL AVAILABILITY OF THE ALTO CAMAQUÃ, RIO GRANDE DO SUL, BRAZIL
}

Nájila Souza da Rocha ${ }^{1}$, Rafael Cabral Cruz ${ }^{2}$, Damáris Gonçalves Padilha ${ }^{3}$, Cibelle Machado Carvalho ${ }^{4}$

\section{RESUMO}

Este trabalho tem como objetivo analisar cenários de fragilidade ambiental dos pecuaristas familiares, frente à redução da disponibilidade hídrica que poderá ocorrer no território do Alto Camaquã devido ao aumento da temperatura previsto nos modelos de mudanças climatológicas inferidos pelo IPCC. Esse território pertence à parte remanescente de maior valor para a biodiversidade do Bioma Pampa, pois compreende uma região que, por suas características econômicas e socioambientais, ainda mantém um ecossistema a priori estável. O sistema de produção, pecuária familiar, ajuda a manter essas condições, porém sofre determinadas demandas do mercado econômico incompatíveis com seu manejo. As mudanças climáticas e ambientais aceleram os processos de intemperismo, de degradação ambiental, além de influenciar os processos do ciclo hidrológico. Este estudo demonstrou que a disponibilidade hídrica e a resistência do solo são as principais variáveis que tornam o Alto Camaquã um território frágil frente ao aumento de temperatura, e os pecuaristas familiares apresentam-se vulneráveis a essas mudanças por não haver instrumentos de mitigação aos impactos ambientais característicos na região e, tampouco, estratégias de gestão para propiciar o aumento da sua resiliência.

Palavras chave: Bioma Pampa. Mudanças climáticas. Pecuária familiar.

\section{ABSTRACT}

This study aims to analyze the vulnerabilities scenarios of livestock family on water front property at temperature rise caused by climate change, in the Alto Camaquã's sub-watershed, inferred by IPCC. This territory belongs to the remaining part of greater value to the biodiversity of the Pampa Biome, because it includes a region that, for their economic, social and environmental characteristics, still maintains a stable ecosystem a priori. The production system, family farming, helps to maintain these conditions, but it suffers certain market demands that are incompatible with their management. In addition, climate and environmental changes that have occurred throughout the planet accelerate weathering processes, environmental degradation and changes the hydrological cycle. This study showed that water availability and soil resistance are variables that make the Alto Camaquã a fragile territorial front to rise temperature caused by climate change. Family farmers are vulnerable to these changes caused by not presenting mitigation instruments of environmental impacts and no increased its resilience strategies.

Keywords: Pampa Biome. Climate change. Family livestock.

\footnotetext{
${ }^{1}$ Universidade Federal do Rio Grande do Sul, Porto Alegre/RS, email: najila.rocha2011@gmail.com

${ }^{2}$ Fundação Universidade Federal do Pampa, Bagé/RS, email: rafaelcabralcruz@gmail.com

${ }^{3}$ Universidade Federal de Santa Maria, Santa Maria/RS, email: damaris.padilha@ufsm.br

${ }^{4}$ Universidade Federal do Pampa, Bagé/RS, email: cibelle_mc@yahoo.com.br
} 


\section{FRAGILIDADES AMBIENTAIS E VULNARABILIDADE DOS PECUARISTAS FAMILIARES FRENTE À DISPONIBILIDADE HÍDRICA DO ALTO CAMAQUÃ/RS}

\section{INTRODUÇÃO}

As mudanças climáticas são uma alteração permanente em um conjunto de condições meteorológicas (temperatura, umidade, chuvas, pressão e ventos) e aconteceram diversas vezes no passado, por causas naturais. Entretanto as atividades humanas, em especial as que utilizam combustíveis fósseis, vêm influenciando a ocorrência desses tipos de evento, por meio da alteração da estabilidade climática do planeta. A causa central desses fenômenos é a intensificação do efeito estufa, que modifica o modo com que a energia solar interage com a atmosfera, provocando consequências, tais como: aumento de temperatura, mudanças no ciclo hidrológico e ocorrência de eventos extremos com maior intensidade (IPCC, 2014).

As previsões do IPCC (Intergovernamental Panel on Climate Change) de 2014 não são otimistas, pois as secas no período de verão tendem a se intensificar e a ocorrerem por períodos mais longos, as chuvas serão menos frequentes e mais intensas nas estações invernais. Além disso, as temperaturas tendem a aumentar em até $7{ }^{\circ} \mathrm{C}$ até 2100 e, superior a este valor, com probabilidade de ocorrência maior de 60\%, até 2150, segundo relatório realizado com apoio da embaixada britânica no Brasil (NOBRE et al., 2016). Esses aumentos modificam, inclusive, os processos de evapotranspiração e, por fim, a disponibilidade hídrica de todo o planeta.

Este estudo foi realizado no Alto Camaquã, localizado na Bacia do Rio Camaquã, em sua parte superior, abrangendo oito municípios do Rio Grande do Sul, todos pertencentes ao Bioma Pampa. Esse território pertence à parte remanescente de maior valor para a biodiversidade do Bioma Pampa, pois compreende uma região que, por suas características econômicas e socioambientais, mantém um ecossistema a priori estável. Esse bioma é dependente da relação pecuária/campo para a sua preservação e conservação, pois é com o pisoteio do gado que as condições ambientais se mantêm (CRUZ; GUADANIN, 2010). Além disso, os pecuaristas familiares são parte importante desse processo, por manterem essa relação com pouca interferência dos modelos econômicos que visam apenas ao extrativismo dos recursos naturais.

Os modelos de fragilidades ambientais devem, de forma integrada e multidisciplinar, refletir os aspectos socioambientais do território em análise, frente às perturbações no meio ambiente e nos recursos naturais. Nesse sentido, dados físicos, sociais, econômicos e bióticos devem ser integrados em uma análise holística multicritério para modelar os ambientes estudados (CEREDA JUNIOR; RÖHM, 2014).

Essas análises têm como objetivo maior evitar, e ou minimizar, a degradação de sistemas auto-organizativos frente às alterações no meio ambiente, mantendo a estabilidade desses sistemas. O conceito de estabilidade e resiliência se define como a habilidade de um sistema absorver as transformações e permanecer em um estado dinâmico (MMA, 2011; 2009). No contexto deste trabalho, a sociedade não é vista apenas como um agente de perturbações, mas também como o objeto do impacto ambiental, ou seja, sofre com as perturbações ambientais. Os meios físico, biótico e antrópico estão inter-relacionados (CARDOSO et al., 2015; CRUZ et al., 2014; COLAVITE; PASSOS, 2012).

Este trabalho tem como objetivo analisar cenários de fragilidade ambiental dos pecuaristas familiares, frente à redução da disponibilidade hídrica que poderá ocorrer no território do Alto Camaquã devido ao aumento da temperatura previsto nos modelos de mudanças climatológicas inferidos pelo IPCC.

\section{MATERIAIS E MÉTODOS}

\subsection{Definição das variáveis do estudo}

Para que as variáveis representassem amplamente, de forma multidisciplinar, o território em análise, fez-se necessária uma revisão bibliográfica sobre as mudanças climáticas previstas e uma seleção preliminar dos aspectos e variáveis considerados mais relevantes para a fragilidade do sistema pecuário familiar. Em seguida, foram analisadas as 


\section{FRAGILIDADES AMBIENTAIS E VULNARABILIDADE DOS PECUARISTAS FAMILIARES FRENTE À DISPONIBILIDADE HÍDRICA DO ALTO CAMAQUÃ/RS}

variáveis disponibilizadas por diferentes órgãos públicos, as quais possuíam as informações necessárias que contemplam as discussões sobre o tema.

Após essa primeira etapa do estudo, identificou-se que as variáveis poderiam ser analisadas em três ambientes distintos: Ambiente Físico; Ambiente Antrópico; e Ambiente Hídrico.

A metodologia utilizada para elaboração dos mapas finais foi a de álgebra de mapas, no software ArcGIS 9.3 (ESRI, 2008), licença concedida à UFSM pela empresa ESRI (Environmentall Systems Reserarch Istitute), que compreende operações matemáticas e de análise espacial aplicados em ambiente de geoprocessamento e que resultam em novas informações (mapas).

Para aplicação da álgebra de mapas, primeiramente é necessário inserir nas variáveis de análise notas de fragilidade às suas classes quali-quantitativas e também pesos de importância em relação a sua interferência no meio. Para isso, foi adaptada a metodologia desenvolvida por MMA (2009) a qual consiste em atribuir notas a um conjunto de classes (de cada variável), que podem variar de 0 a 255 (níveis de cinza), sendo que quanto maior a nota atribuída mais frágil é a classe.

As notas, de cada classe das variáveis, são somadas pixel a pixel, por meio de média ponderada dos pesos atribuídos conforme valor de importância para cada variável. Por fim, são criados os cenários de fragilidade para cada ambiente. Os pesos referidos acima são aqueles utilizados na matemática para atribuir importância diferente a cada valor, sendo que esses devem somar $100 \%$ em cada avaliação (CARDOSO et. al., 2015).

As notas dadas para cada classe das variáveis foram relativas à vulnerabilidade da variável frente ao déficit hídrico causado, ou não, pelo aumento de temperatura previsto pelo IPCC em caso de mudança climática. Ainda, quando necessário, professores e pesquisadores do Programa de Pós-Graduação em Engenharia Ambiental da Universidade Federal de Santa Maria (PPGEAmb-UFSM) foram consultados sobre quais as classes deveriam ser consideradas mais frágeis neste estudo.

\subsection{Ambiente Físico - fragilidade física}

Neste ambiente foram consideradas três variáveis. A primeira é o mapa de Capacidade Máxima de Água Disponível (CAD), termo que representa o limite de água entre a capacidade de campo (CC) e o ponto de murcha permanente (PMP). Segundo Carvalho Neto (2014), com a análise desses limites, pode-se determinar a capacidade de armazenamento de água disponível no solo, considerando a profundidade do sistema radicular.

Conforme o uso e cobertura do solo, disponibilizado pelo Instituto Brasileiro de Geografia e Estatística (IBGE, 2007), foram determinadas as CADs para a sub-bacia de estudo, como apresentado na Tabela 1 . Os valores de referência utilizados para essa variável foram estipulados por Pereira et al. (2002) apud Carvalho Neto (2014) e adaptados para os solos da Secretaria Estadual do Meio Ambiente (2010) pelo mesmo autor.

Para a análise da fragilidade foram consideradas que as áreas que possuem menor capacidade de água disponível são mais frágeis frente ao déficit hídrico causado ou não pelas mudanças climáticas, portanto possuem maior nota (255). Isso ocorre porque quanto menor a $C A D$, mais água será escoada e menos água estará disponível para as plantas. 
ROCHA, N. S., CRUZ, R. C., PADILHA, D. C., CARVALHO, C. M.

\section{FRAGILIDADES AMBIENTAIS E VULNARABILIDADE DOS PECUARISTAS FAMILIARES FRENTE À DISPONIBILIDADE HÍDRICA DO ALTO CAMAQUÃ/RS}

Tabela 1 - Capacidade máxima de água disponível definidos para o uso e ocupação do solo do Alto Camaquã

\begin{tabular}{lll}
\hline Uso e ocupação do solo & CAD & $\begin{array}{l}\text { Fragilidade } \\
\text { (nota) }\end{array}$ \\
\hline Silvicultura & 100 & 64 \\
Pastagem Pecuária & 60 & 128 \\
Pastagem + Lavoura arroz & 60 & 128 \\
Pastagem + Lavoura & 60 & 128 \\
Vegetação Campestre + Pastagem + Lavoura Diversificada & 60 & 128 \\
Vegetação Campestre + Pastagem & \multicolumn{2}{|c}{} \\
Vegetação Florestal + Lavoura + Pastagem & 60 & 128 \\
Lavoura Soja/Trigo & 60 & 128 \\
Área Urbanizada & 20 & 192 \\
Mineração & 0 & 255 \\
\hline
\end{tabular}

Fonte: ROCHA (2016).

A segunda variável analisada no Ambiente Físico é mapa de classificação dos solos do estado do RS, quanto à resistência aos impactos ambientais, na escala 1:250.000, elaborado por Nestor Kampf para Fepam (2001), o qual contempla, na região de abrangência do projeto, quatro classes de solos. Estas classes de solos possuem variada resistência a impactos ambientais, em função de sua profundidade, textura, gradiente textural, drenagem, nível freático, lençol suspenso, risco de inundação, susceptibilidade à erosão, relevo, declividade, aptidão agrícola e tipo de argilomineral (MMA, 2011).

Essa variável abrange tantas características físicas do solo que sua utilização sintetiza a utilização de outros mapas básicos, como relevo e declividade. De acordo com os fatores do solo ou do terreno, essa variável foi classificada em quatro classes de resistência a impactos ambientais como consta no relatório da Fepam (2001): alta (a); média (b); baixa (c) e muito baixa (d). Essas classes receberam notas de fragilidade, como segue: (a)64; (b)128; (c)192 e (d) 255.

A terceira e última variável desse ambiente é o uso e ocupação do solo, as classes são as mesmas utilizadas para a construção da $C A D$, porém receberam notas de fragilidade referentes à sua importância para a preservação e conservação do ecossistema do Bioma Pampa e da manutenção dos pecuaristas familiares no território frente às mudanças que estão sendo estudadas nesta pesquisa.

O uso e ocupação do solo e as classes foram definidos conforme o mapa disponibilizado pelo IBGE (2007). Foi estabelecido que, quanto mais propício o uso for para a produção pecuária e manutenção dos agricultores na região, maior será a nota atribuída, pois maior importância se dá a essas áreas. Além disso, sistemas produtivos mais dependentes da água foram considerados mais frágeis que sistemas mais adaptados ao déficit hídrico. Na Tabela 2 são apresentadas as notas para cada classe. 
ROCHA, N. S., CRUZ, R. C., PADILHA, D. C., CARVALHO, C. M.

\section{FRAGILIDADES AMBIENTAIS E VULNARABILIDADE DOS PECUARISTAS FAMILIARES FRENTE À DISPONIBILIDADE HÍDRICA DO ALTO CAMAQUÃ/RS}

Tabela 2 - Classes e fragilidades (notas) do uso e ocupação do solo no território do Alto Camaquã

\begin{tabular}{ll}
\hline Uso Solo & Fragilidade (nota) \\
\hline Mineração & 28 \\
Silvicultura & 57 \\
Vegetação Florestal + Lavoura + Pastagem & 85 \\
Lavoura Soja/Trigo & 113 \\
Vegetação Campestre + Pastagem & 140 \\
Vegetação Campestre + Pastagem + Lavoura Diversificada & 170 \\
Pastagem + Lavoura & 197 \\
Pastagem + Lavoura arroz & 224 \\
Pastagem Pecuária & 255 \\
\hline
\end{tabular}

Fonte: ROCHA (2016).

\subsection{Atribuição de pesos e análise de sensibilidade}

Segundo Padilha et. al. (2014) "cabe à equipe ou ao projetista, identificar quais serão os $n$ fatores que farão parte da avaliação em cada um dos ambientes, assim como a definição de sua importância relativa dentro do modelo".

Essa afirmação é corroborada por Santos (2004), quando afirma que há sempre uma ou mais alternativas de solução para um mesmo problema no decorrer de um planejamento. Aos pesquisadores/planejadores cabe encontrar alternativas que diminuam os erros e apresentem alternativas aos tomadores de decisão.

Uma das alternativas para diminuir as incertezas nos modelos de análise multicritério, quanto à ponderação das variáveis do estudo, proposta por Trevisan (2008) é a análise de sensibilidade. Esta análise pode revelar redundância entre fatores, evidenciando a importância de outros e reduzindo discussões quanto à ponderação das variáveis.

O conceito de sensibilidade "considera as diferenças entre os fatores (mapas) resultantes de processamento da avaliação multicritério quando se faz a variação do peso de um fator mantendo-se os demais iguais" (PADILHA et al., 2014). Segundo os mesmos autores, essa análise necessita da construção de um cenário testemunha (CT), em que seus indicadores (variáveis) possuam o mesmo valor de importância.
Sendo assim, esse cenário homogêneo servirá de referencial para a avaliação da diversidade possível de ser revelada em outros cenários ponderados. Essa metodologia foi descrita por Padilha et al. (2014) e será a mesma desenvolvida nesta análise.

O cenário testemunha caracteriza-se por não priorizar nenhum dos temas de sua composição, sendo por isso a situação menos desejável em uma ponderação multicriterial. Portanto, o método para testar a sensibilidade consiste em comparar as matrizes (rasters) sistematicamente ponderadas, a fim de, diferentemente dos casos estatísticos clássicos, em que se busca a aproximação a uma curva de tendência, encontrar as composições que mais se afastem dessa tendência. Em outras palavras, ao adotar o cenário homogêneo como testemunha (ou "cenário esperado"), os resultados de uma análise de sensibilidade são tão mais convenientes (desejáveis) quanto mais afastados da tendência testemunhal, explicando-se dessa forma a inversão estatística (PADILHA et. al., 2014, p. 541).

Como a Fragilidade Física possui três variáveis de estudo, temos que: F1 (Fator 1) é Uso do Solo; F2 (Fator 2) é Resistência do Solo; e F3 (Fator 3) é CAD. Foram criados cinco cenários diferentes para cada fator colocado em evidência, com valores de 0 à $50 \%$, sempre somando $100 \%$ na ponderação, como apresentado na Tabela 3. 
ROCHA, N. S., CRUZ, R. C., PADILHA, D. C., CARVALHO, C. M.

\section{FRAGILIDADES AMBIENTAIS E VULNARABILIDADE DOS PECUARISTAS FAMILIARES FRENTE À DISPONIBILIDADE HÍDRICA DO ALTO CAMAQUÃ/RS}

A estatística utilizada foi a correlação de Pearson disponível na rotina Spatial Analist Tools/Multivariate/Band Collections Statistics, no software ArcGIS 9.3. Os resultados dessa estatística são apresentados na Tabela 4. Segundo essa metodologia os valores que se afastam mais de 1 são considerados os melhores cenários para representar o território.
Esses resultados demonstram que 0 cenário F1C1 representa melhor a realidade, pois o resultado da estatística foi 0,84 , aquele que mais se distancia do CT. Por outro lado, os cenários C3 e C4 são aqueles que mais se aproximam do cenário testemunha (CT) e, portanto, representariam condições muito homogêneas e distantes da realidade.

Tabela 3 - Ponderação das variáveis para análise de sensibilidade

\begin{tabular}{|c|c|c|c|c|c|c|c|}
\hline Fator & Variável & $\mathrm{CT}$ & $\mathrm{C} 1$ & $\mathrm{C} 2$ & C3 & $\mathrm{C} 4$ & C5 \\
\hline $\begin{array}{l}\text { F1 sob } \\
\text { ponderação }\end{array}$ & Uso do Solo & $33,33 \%$ & $10 \%$ & $20 \%$ & $30 \%$ & $40 \%$ & $50 \%$ \\
\hline F2 fixo & Resistência do Solo & $33,33 \%$ & $45 \%$ & $40 \%$ & $35 \%$ & $30 \%$ & $25 \%$ \\
\hline F3 fixo & CAD & $33,33 \%$ & $45 \%$ & $40 \%$ & $35 \%$ & $30 \%$ & $25 \%$ \\
\hline Fator & Variável & $\mathrm{CT}$ & $\mathrm{C} 1$ & $\mathrm{C} 2$ & $\mathrm{C} 3$ & $\mathrm{C} 4$ & $\mathrm{C} 5$ \\
\hline F1 fixo & Uso do Solo & $33,33 \%$ & $45 \%$ & $40 \%$ & $35 \%$ & $30 \%$ & $25 \%$ \\
\hline $\begin{array}{l}\text { F2 sob } \\
\text { ponderação }\end{array}$ & Resistência do Solo & $33,33 \%$ & $10 \%$ & $20 \%$ & $30 \%$ & $40 \%$ & $50 \%$ \\
\hline F3 fixo & CAD & $33,33 \%$ & $45 \%$ & $40 \%$ & $35 \%$ & $30 \%$ & $25 \%$ \\
\hline Fator & Variável & $\mathrm{CT}$ & $\mathrm{C} 1$ & $\mathrm{C} 2$ & $\mathrm{C} 3$ & $\mathrm{C} 4$ & $\mathrm{C} 5$ \\
\hline F1 fixo & Uso do Solo & $33,33 \%$ & $45 \%$ & $40 \%$ & $35 \%$ & $30 \%$ & $25 \%$ \\
\hline F2 fixo & Resistência do Solo & $33,33 \%$ & $45 \%$ & $40 \%$ & $35 \%$ & $30 \%$ & $25 \%$ \\
\hline $\begin{array}{l}\text { F3 sob } \\
\text { ponderação }\end{array}$ & CAD & $33,33 \%$ & $10 \%$ & $20 \%$ & $30 \%$ & $40 \%$ & $50 \%$ \\
\hline
\end{tabular}

Fonte: ROCHA (2016).

Tabela 4 - Resultado da análise estatística de Pearson

\begin{tabular}{llllll}
\hline & C1 $(0,1)$ & C2 $(0,2)$ & C3 $(0,3)$ & C4 $(0,4)$ & C5 $(0,5)$ \\
\hline CT X F1 & 0,84204 & 0,94989 & 0,99721 & 0,99073 & 0,95356 \\
CT X F2 & 0,86285 & 0,9487 & 0,9966 & 0,9864 & 0,92401 \\
CT X F3 & 0,98021 & 0,99219 & 0,99935 & 0,99739 & 0,97992 \\
\hline
\end{tabular}

Fonte: ROCHA (2016).

A fragilidade física do território é altamente influenciada pelo mapa de resistência do solo, justamente por este apresentar a classe muito baixa resistência na maior parte do território.

As regiões a oeste da sub-bacia possuem menor fragilidade física, justamente porque os solos dessa região são mais resistentes a impactos ambientais. Já as regiões ao centro da bacia, que possuem muito baixa resistência do solo, são as áreas de maior fragilidade física.

\subsection{Fragilidade do Ambiente Antrópico}

Considerando que a problemática deste estudo está relacionada diretamente com a pecuária familiar, utilizaram-se dados disponibilizados pelo IBGE do censo agrícola do ano de 2006, para caracterizar o território segundo a presença de estabelecimentos de 
ROCHA, N. S., CRUZ, R. C., PADILHA, D. C., CARVALHO, C. M.

\section{FRAGILIDADES AMBIENTAIS E VULNARABILIDADE DOS PECUARISTAS FAMILIARES FRENTE À DISPONIBILIDADE HÍDRICA DO ALTO CAMAQUÃ/RS}

agricultura familiar e de produção pecuária. Os

estão

apresentados

na Tabela

5.

Tabela 5 - Características sociais do Alto Camaquã

\begin{tabular}{cccc}
\hline Município & $\begin{array}{c}\text { Estabelecimentos } \\
\text { Agropecuários }\end{array}$ & $\begin{array}{c}\text { Estabelecimentos de } \\
\text { Pecuária (\%) }\end{array}$ & $\begin{array}{c}\text { Estabelecimentos de } \\
\text { Agricultura Familiar (\%) }\end{array}$ \\
\hline Dom Pedrito & 1439 & 75,33 & 49,55 \\
Encruzilhada do Sul & 2724 & 75,4 & 76,8 \\
Caçapava do Sul & 3383 & 77,89 & 77,95 \\
Lavras do Sul & 884 & 82,58 & 66,52 \\
Pinheiro Machado & 1605 & 83,3 & 72,15 \\
Bagé & 1199 & 83,32 & 59,47 \\
Santana da Boa Vista & 1631 & 85,84 & 81,97 \\
Piratini & 2902 & 87,56 & 77,6 \\
Hulha Negra & 1030 & 88,54 & 84,27 \\
\hline
\end{tabular}

Fonte: IBGE, Censo Agrícola (2006).

Essas duas variáveis (agricultura familiar e produção pecuária) formam o Ambiente Antrópico deste estudo, gerando uma fragilidade do ponto de vista social. Considerou-se que as duas variáveis possuem o mesmo valor de importância neste estudo, portanto receberam pesos iguais $(50 \%$ cada). A fragilidade do ambiente antrópico gerada é uma das mais homogêneas, isso porque as variáveis utilizadas não possuem notas de fragilidades muito baixas.

Foi considerado que se $100 \%$ do território do município possuísse estabelecimentos de "Pecuária" teria a nota máxima de fragilidade (255), pois esses são os estabelecimentos foco deste estudo, por manterem as melhores condições desse ecossistema e não apresentarem capacidade de resiliência frente às alterações previstas, segundo estudos realizados por Carvalho (2014) e Neske (2009).

Sendo assim, a partir de regra de três simples foram estabelecidas as notas de fragilidade para essa variável. Seguiu-se o mesmo raciocínio para a variável agricultura familiar. Se $100 \%$ dos estabelecimentos agropecuários fossem de agricultura familiar, o município receberia nota máxima de fragilidade (255). Também foi realizada regra de três simples para a criação de notas dessa variável (Tabela 6).

Tabela 6 - Notas de fragilidade das variáveis Pecuária e Agricultura familiar nos municípios da bacia do Alto Camapuã

\begin{tabular}{ccc}
\hline Município & Fragilidade Pecuária & Fragilidade Agricultura Familiar \\
\hline Dom Pedrito & 192 & 126 \\
Encruzilhada do Sul & 192 & 152 \\
Caçapava do Sul & 199 & 170 \\
Lavras do Sul & 211 & 184 \\
Pinheiro Machado & 212 & 196 \\
Bagé & 212 & 198 \\
Santana da Boa Vista & 219 & 199 \\
Piratini & 223 & 209 \\
Hulha Negra & 226 & 215 \\
\hline
\end{tabular}




\section{FRAGILIDADES AMBIENTAIS E VULNARABILIDADE DOS PECUARISTAS FAMILIARES FRENTE À DISPONIBILIDADE HÍDRICA DO ALTO CAMAQUÃ/RS}

Fonte: ROCHA (2016).

Os municípios do centro da bacia possuem uma fragilidade um pouco menor. Entre eles, está o município de Piratini, um dos que possui maior presença de pecuária de agricultura familiar. Já os municípios a oeste possuem menor presença de agricultura familiar e são menos vulneráveis às mudanças climáticas consideradas neste artigo, pois seus modelos de produção são menos dependentes dos recursos hídricos naturais.

\subsection{Ambiente Hídrico - Fragilidade Hídrica}

O Ambiente Hídrico é referente aos resultados das médias anuais dos BHC. Foram criados seis cenários de BHC, dos quais três são cenários atuais (CA) de déficit hídrico para os três anos de referência estudados (Ano Normal; Ano Chuvoso; e Ano Seco). Os outros três cenários são os anos com aumento de temperatura, chamados de Cenário com Mudança de Temperatura (CMT) para cada ano de referência citado anteriormente.

Os três anos de referência utilizados foram escolhidos a partir da análise dos dados de chuvas de 14 estações pluviométricas. A série histórica utilizada foi de 1990 até 2013, excluindo anos com dados inconsistentes. Foi realizada a média pluviométrica anual para os 23 anos estudados para cada ponto pluviométrico (média geral), visando a entender o comportamento das chuvas no ponto. A partir daí, foram selecionados três anos para cada ponto, chamados aqui de: Ano Normal; Ano Seco e Ano Chuvoso. Sendo Ano Normal aquele que a média pluviométrica mais se aproxima da média geral; Ano Seco aquele que possui menor precipitação ao longo do ano, ou seja, sua média anual está muito abaixo da média geral; e Ano Chuvoso aquele que possui maior precipitação ao longo do ano, ou seja, sua média anual está muito acima da média geral.

Para estabelecer a fragilidade de cada cenário, fez-se necessário conhecer os valores mínimos e máximos de déficit/excedente hídrico para cada ano de referência, com e sem mudança de temperatura. $O$ valor máximo de déficit hídrico, de todos os anos, foi de cem milímetros $(-100 \mathrm{~mm})$ e o valor máximo de excedente hídrico chegou a duzentos milímetros $(200 \mathrm{~mm})$.

Os valores foram divididos em 10 classes de fragilidade com intervalos de $30 \mathrm{~mm}$ cada. As notas de fragilidade também foram divididas em 10 classes, apresentados na Tabela 7.

Tabela 7 - Classes de Balanço Hídrico Climatológico e notas de fragilidade

\begin{tabular}{cc}
\hline Dados de BHC & Notas \\
\hline$-100--69$ & $255-229$ \\
$-70--39$ & $230-203$ \\
$-40--9$ & $204-179$ \\
$-10-19$ & $180-153$ \\
$20-49$ & $154-130$ \\
$50-79$ & $129-105$ \\
$80-109$ & $104-78$ \\
$110-139$ & $79-53$ \\
$140-169$ & $54-28$ \\
$170-200$ & $29-0$ \\
\hline
\end{tabular}

Fonte: ROCHA (2016). 
ROCHA, N. S., CRUZ, R. C., PADILHA, D. C., CARVALHO, C. M.

\section{FRAGILIDADES AMBIENTAIS E VULNARABILIDADE DOS PECUARISTAS FAMILIARES FRENTE À DISPONIBILIDADE HÍDRICA DO ALTO CAMAQUÃ/RS}

Foi gerada uma função linear (1) para definir os valores ponderados dentro das classes, conforme a equação (1).

$$
y=-0,842 x+171
$$

Cada mapa de déficit hídrico possui o seu máximo de déficit e excedente hídrico e suas próprias classes. Os valores inferiores das classes de cada ano são os valores de $x$ (dado); os valores $y$ são as notas de fragilidade, calculados a partir da função estabelecida anteriormente (Tabela 8).

Tabela 8 - Dados de BHC e notas de fragilidade para cada ano.

\begin{tabular}{|c|c|c|c|c|c|}
\hline \multicolumn{2}{|c|}{ Seco (CA) } & \multicolumn{2}{|c|}{ Chuvoso (CA) } & \multicolumn{2}{|c|}{ Normal (CA) } \\
\hline Dado & Nota & Dado & Nota & Dado & Nota \\
\hline 7,73 & 165 & 108,92 & 79 & 43 & 135 \\
\hline 11,85 & 161 & 120,29 & 70 & 46,39 & 132 \\
\hline 14,83 & 159 & 131,45 & 60 & 49,87 & 129 \\
\hline 17,7 & 156 & 142,43 & 51 & 56,18 & 124 \\
\hline 25,95 & 149 & 159,38 & 37 & 67,36 & 114 \\
\hline \multicolumn{2}{|c|}{ Seco (CMT) } & \multicolumn{2}{|c|}{ Chuvoso (CMT) } & \multicolumn{2}{|c|}{ Normal (CMT) } \\
\hline Dado & Nota & Dado & Nota & Dado & Nota \\
\hline-75 & 234 & 28,63 & 147 & $-32,17$ & 198 \\
\hline-66 & 227 & 43,76 & 134 & $-25,69$ & 193 \\
\hline-61 & 222 & 58,35 & 122 & $-17,81$ & 186 \\
\hline-56 & 218 & 68,8 & 113 & $-2,55$ & 173 \\
\hline-44 & 208 & 83,93 & 100 & 17,51 & 156 \\
\hline
\end{tabular}

Fonte: ROCHA (2016).

Essas notas foram dadas, pixel a pixel, por meio da função Reclassify, no software ArcGIS 9.3, na rotina 3D Analyst Tools - Raster Reclass. Os cenários atuais (CA) gerados possuem uma nota de fragilidade mínima de 37 e máxima de 165 , sendo possível perceber o aumento na fragilidade para o Ano Normal e Ano Seco, em relação ao Ano Chuvoso. A região de Torrinhas e a região de Paraíso possuem uma maior variação na fragilidade, como mostra a Figura 1 .

O Ano Seco (CA) possui alta fragilidade, em toda a sub-bacia. Nesse cenário a fragilidade varia de 149 até 165, um aumento de 18,2\% de fragilidade em relação ao Ano Normal (CA) e um aumento de $52 \%$ em relação ao Ano Chuvoso (CA).

A fragilidade hídrica nos cenários com mudança de temperatura (CMT) aumentou para um mínimo de 100 e máximo de 234. Mais uma vez o ponto Paraíso possui maior variabilidade de fragilidade. O "Ano Chuvoso" possui baixa fragilidade, de maneira bem homogênea em todo o território (Figura 1b). 
ROCHA, N. S., CRUZ, R. C., PADILHA, D. C., CARVALHO, C. M.

\section{FRAGILIDADES AMBIENTAIS E VULNARABILIDADE DOS PECUARISTAS FAMILIARES FRENTE À DISPONIBILIDADE HÍDRICA DO ALTO CAMAQUÃ/RS}
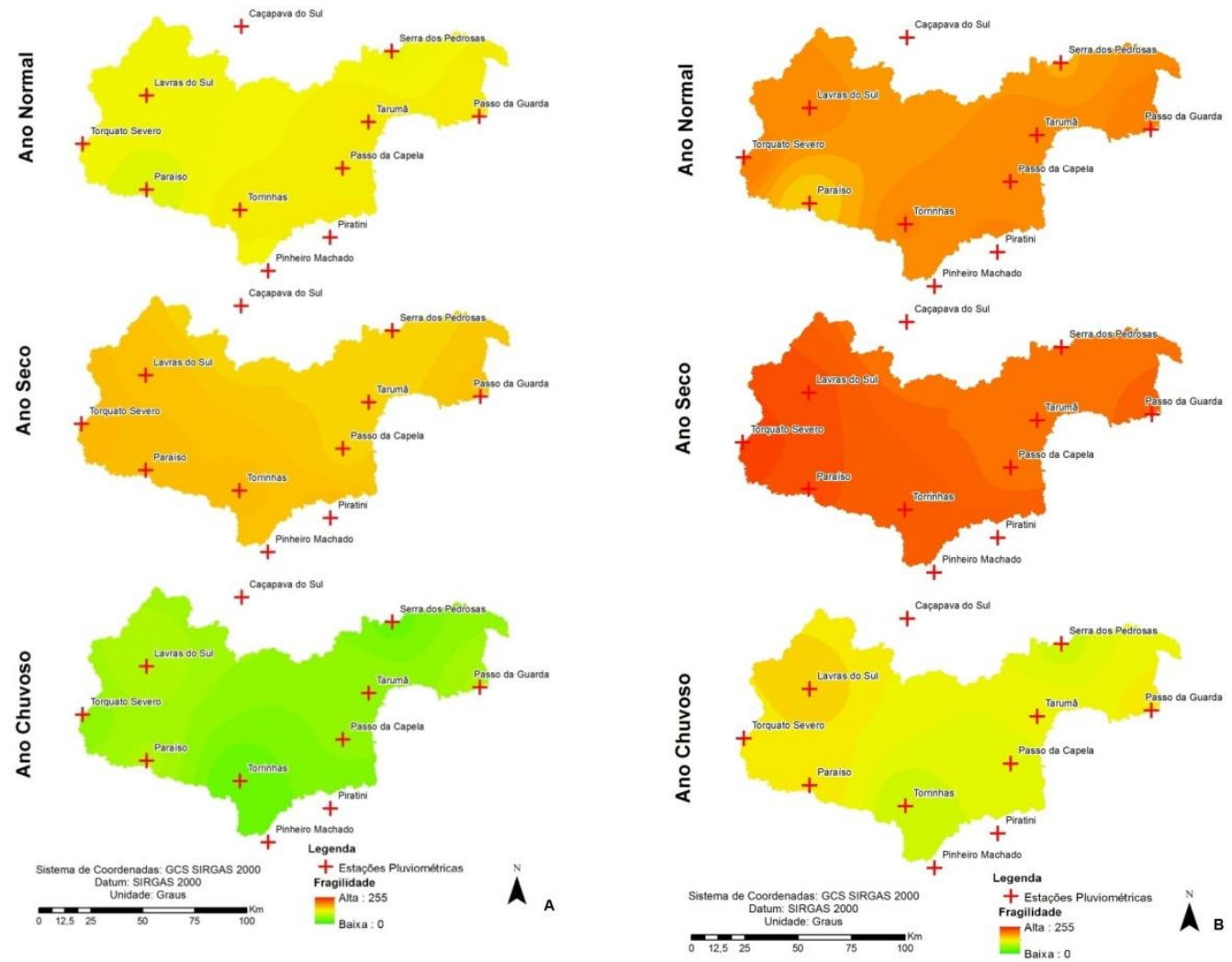

Figura 1 - Fragilidade Hídrica. a) Cenário atual; b) Cenário com aumento de temperatura. Fonte: ROCHA (2016).

O Ano Seco passa a ter uma pequena variação de fragilidade, ao nordeste da bacia, nos pontos Passo da Capela, Tarumã e Serra dos Pedrosas, porém a fragilidade continua sendo alta em relação aos outros anos. Há um aumento de $15,4 \%$ da fragilidade máxima do Ano Seco em relação ao Ano Normal e de $37,17 \%$ em relação ao

Ano

Chuvoso. 
ROCHA, N. S., CRUZ, R. C., PADILHA, D. C., CARVALHO, C. M.

\section{FRAGILIDADES AMBIENTAIS E VULNARABILIDADE DOS PECUARISTAS FAMILIARES FRENTE À DISPONIBILIDADE HÍDRICA DO ALTO CAMAQUÃ/RS}

CRIAÇÃO DOS CENÁRIOS DE FRAGILIDADE AMBIENTAL

O primeiro cenário a ser criado foi o chamado de Fragilidade Física-Social, pois se compilou o Ambiente Físico com o Ambiente Antrópico, cada qual recebeu peso de $50 \%$ (Figura 2). Os pontos das estações pluviométricas servem de referência apenas para indicarmos as regiões com maior ou menor fragilidade.
Se levássemos em consideração apenas essas variáveis para análise de fragilidade, poderíamos afirmar que as regiões de Paraíso, Torquato Severo, Passo da Capela possuem menor fragilidade em um cenário atual. Porém as regiões centrais do território Alto Camaquã, além Torrinhas e Tarumã, possuem alta fragilidade.

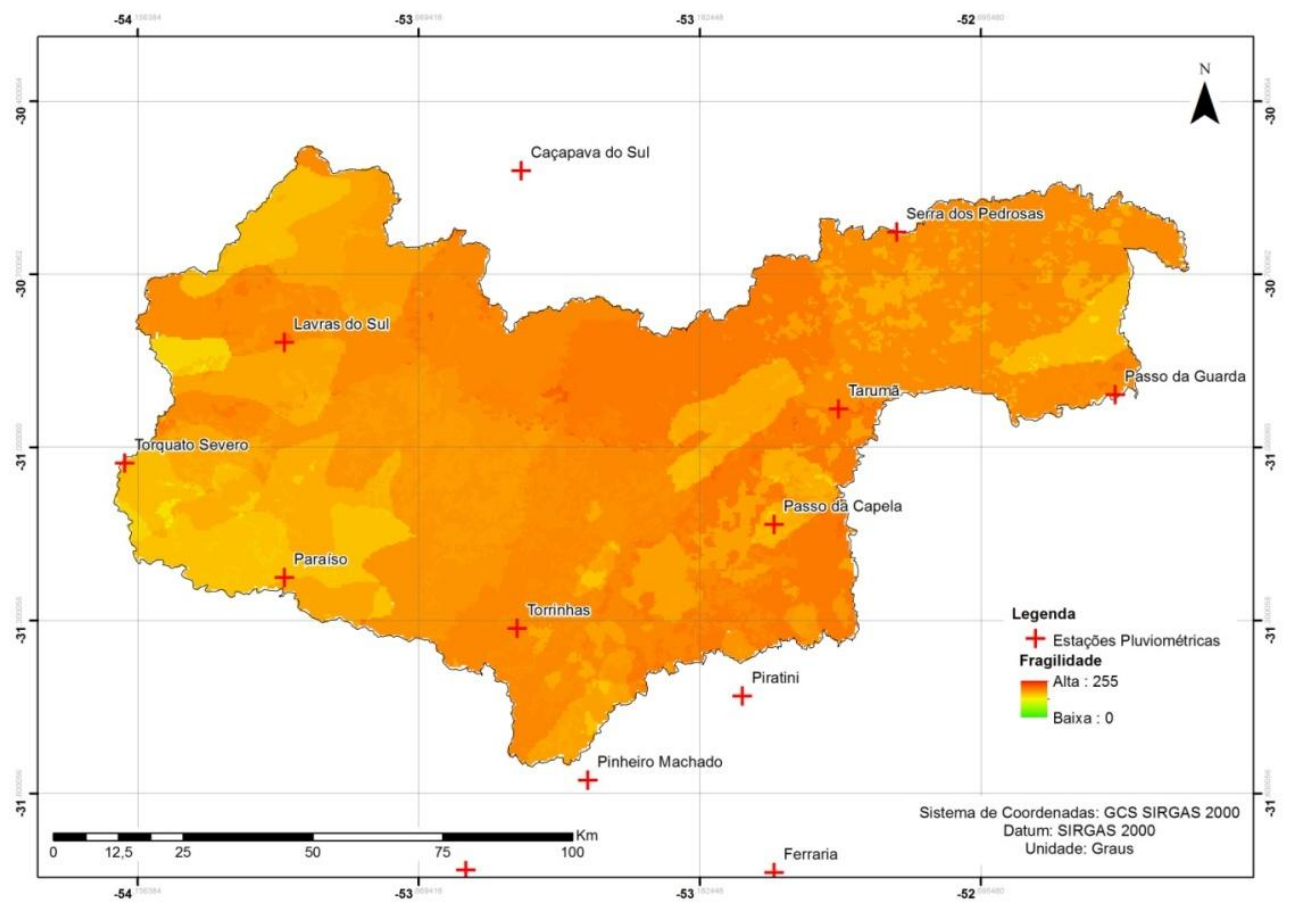

Figura 2 - Cenário da Fragilidade Física-Social Fonte: ROCHA (2016).

O território de estudo não possui regiões com fragilidade abaixo de 125 , ou seja, todo o território possui média e alta fragilidade. Esses resultados demonstram que essa é uma subbacia que merece atenção, e que, por suas características físicas e sociais, deve sofrer intervenções que visem a minimizar as vulnerabilidades da região.

Após essa primeira análise, foram criados seis cenários para análise final de fragilidade ambiental. Esses seguiram a lógica de pensamento dos cenários criados no Ambiente Hídrico, ou seja, foram levados em consideração os cenários de Ano Seco, Ano Chuvoso e Ano Normal, tanto sem mudanças de temperatura tanto com mudanças. Os cenários de déficit hídrico são aqueles que definem a problemática de déficit hídrico, ponto central neste trabalho. Por esse mesmo motivo, esse é o ambiente com maior valor de importância em todos os cenários.

Os cenários finais foram elaborados a partir da função álgebra de mapas, sendo somados o mapa de fragilidade física-social e o mapa de fragilidade hídrica de cada ano de referência, gerando, assim, o mapa de fragilidade ambiental para cada cenário.

\section{RESULTADOS E DISCUSSÕES}

Os cenários criados para representar a fragilidade ambiental do Alto Camaquã 
ROCHA, N. S., CRUZ, R. C., PADILHA, D. C., CARVALHO, C. M.

\section{FRAGILIDADES AMBIENTAIS E VULNARABILIDADE DOS PECUARISTAS FAMILIARES FRENTE À DISPONIBILIDADE HÍDRICA DO ALTO CAMAQUÃ/RS}

demonstram que, se a bacia tivesse um comportamento como o do Ano Chuvoso, a subbacia apresentaria baixa fragilidade, com notas que variam de 92 a 145. Os cenários de Ano Seco e Ano Normal representam melhor a realidade do território, com média e alta fragilidade, principalmente na região central (Figura 3a).

O cenário Ano Normal representa melhor a realidade da bacia nos dias atuais, pois esse discrimina melhor as regiões de maior e menor fragilidade. Os pontos Tarumã e Torrinhas são pontos de referência de maior fragilidade.

A região central, com a maior fragilidade, possui solos de mais baixa resistência, declividade acentuada, solos rasos e pedregosos. Além disso, maior concentração de pecuaristas e agricultores familiares. Segundo Carvalho (2015), o projeto Desenvolvimento Territorial Endógeno no Alto Camaquã, desenvolvido pela Embrapa Pecuária Sul, demonstra ser uma ferramenta importante para o empoderamento dos pecuaristas familiares e para o aumento de sua resiliência perante aos impactos ambientais.

Esses resultados comprovam análises de trabalhos qualitativos anteriores. Matte (2013) considera que a pecuária de corte, em todas as suas formas sociais e produtivas, encontra-se em exposição a situações de vulnerabilidade, isso porque a Serra do Sudeste do Rio Grande do Sul vem sendo submetida aos efeitos de transformações envolvendo dinâmicas socioeconômicas, fundiárias e ambientais.

Para Carvalho (2015), a produção pecuária do Alto Camaquã representa estratégias de revalorização da produção local que se aproxima de contextos internacionais. Apresentam um produto de qualidade particular, associado a um lugar, a um modo de vida e de produção, com uma história preservada a mais de dois séculos.

Os cenários de déficit e excedente hídrico demonstraram que os meses de janeiro e fevereiro, inclusive no Ano Chuvoso, possuem déficit hídrico e portanto fragilidade alta. O Ano Seco poderia, em uma situação hipotética, representar a fragilidade dos meses mais críticos de disponibilidade hídrica. 


\section{FRAGILIDADES AMBIENTAIS E VULNARABILIDADE DOS PECUARISTAS FAMILIARES FRENTE À DISPONIBILIDADE HÍDRICA DO ALTO CAMAQUÃ/RS}
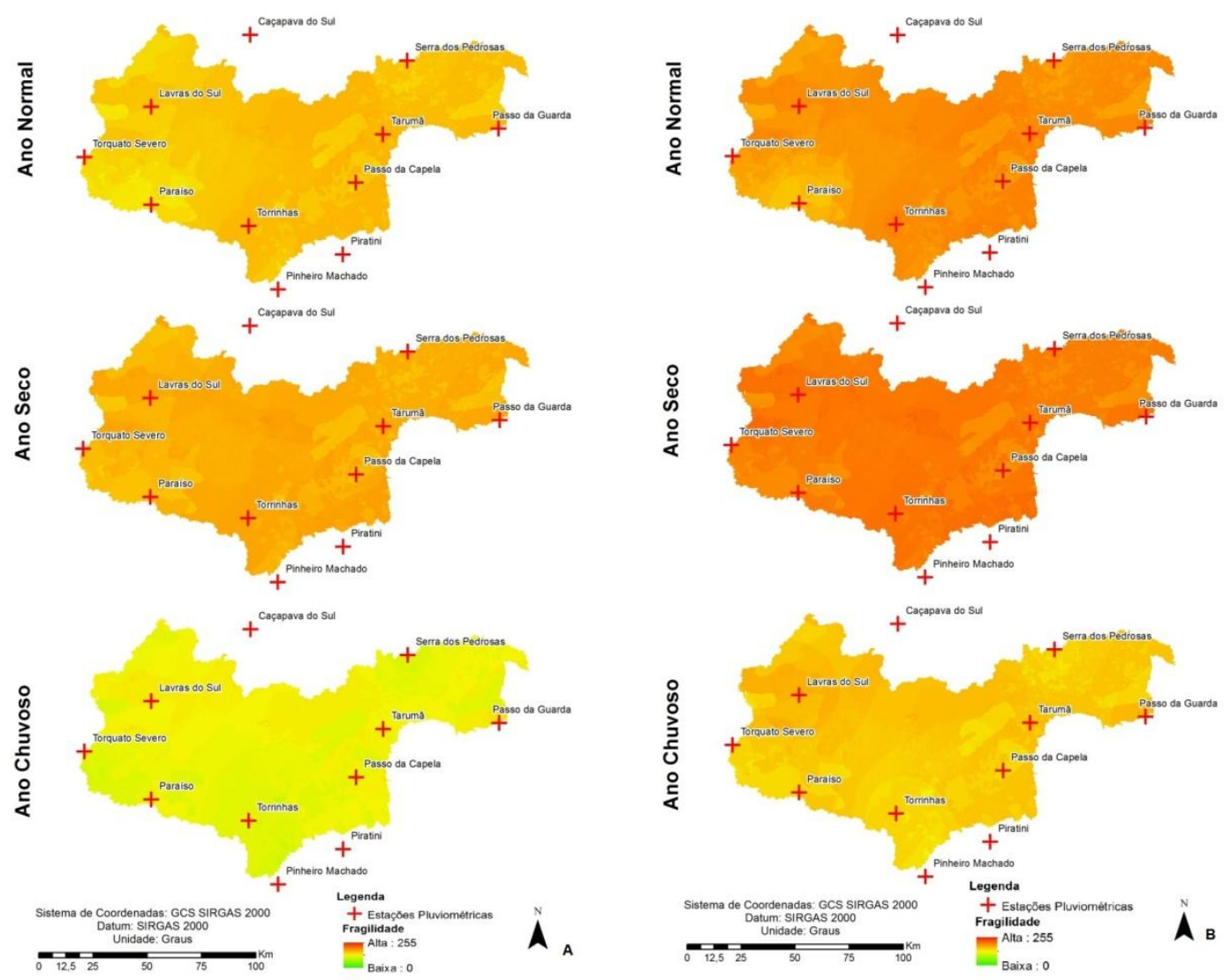

Figura 3 - Fragilidade Ambiental. a) Cenário atual; b) Cenário com aumento de temperatura. Fonte: ROCHA (2016).

Para tanto, a conservação atual do Alto Camaquã e a diminuição de tal fragilidade, necessitam de apoio técnico e político, fomentado por projetos endógenos que valorizem a existência dos campos nativos e a biodiversidade local. Carvalho et al. (2014) lembram que esse território ainda presta serviços ambientais fundamentais para o território e a sociedade, como: ciclagem de nutrientes, produção e conservação de solos, infiltração da água no solo, captação de carbono da atmosfera, presença de polinizadores, entre tantos outros benefícios.

Nos cenários de mudança de temperatura (Figura 3b), a fragilidade aumenta em todas as circunstâncias. Os resultados demonstram que mesmo em um cenário otimista de Ano Chuvoso, as fragilidades aumentariam para um mínimo de 129 e máximo de 178. Os territórios, que antes não apresentavam situações graves de fragilidade nos anos Seco e Normal, passam a apresentar alta fragilidade.

Os cenários de mudança de temperatura são importantes para que se compreenda a gravidade do problema de déficit hídrico no território, caso as previsões do IPCC (2014) se confirmem. Espera-se que esses cenários sirvam de alerta para que os órgãos competentes possam vislumbrar, de uma maneira mais holística, o quão vulnerável está esse território diante das previsões.

Carvalho (2015) demonstrou que o Alto Camaquã é uma região esquecida pelos órgãos públicos, inclusive pelo comitê de bacia do Rio Camaquã. Ainda, a Embrapa apareceu nos resultados como único representante político para os pecuaristas familiares. Grande parte dos atores sociais entrevistados não reconhece nenhum órgão público, vereadores e políticos 


\section{FRAGILIDADES AMBIENTAIS E VULNARABILIDADE DOS PECUARISTAS FAMILIARES FRENTE À DISPONIBILIDADE HÍDRICA DO ALTO CAMAQUÃ/RS}

como representantes, identificando a falta de vozes ativas na região.

Para Roboredo et. al. (2016), os agricultores deveriam estar envolvidos no processo de construção de alternativas para melhoria socioambiental dos territórios em que vivem; esse seria um dos pré-requisitos para atingir o desenvolvimento de forma sustentável.

\section{CONCLUSÕES}

Este estudo, mesmo considerando que os efeitos das mudanças climáticas tenham sido indicados unicamente pelo aumento de temperatura, permite concluir que o território do Alto Camaquã é frágil aos impactos ambientais causados pelo déficit hídrico. Os efeitos dessa fragilidade poderão ser cumulativos e sinérgicos quando levadas em consideração as previsões dos modelos do IPCC, de alongamento das estações de seca.

As diferentes contribuições de precipitação, analisadas neste trabalho a partir da média dos anos mais chuvosos, anos com médias normais e dos anos mais secos, apresentaram resultados coerentes com a situação atual e futura da região de estudo.

Os cenários de Ano Normal e Ano Seco representaram melhor as condições ambientais do território, demonstrando média e alta fragilidade na região central da sub-bacia. Nesse contexto, o Ano Seco representa alta fragilidade dos meses mais críticos de disponibilidade hídrica, enquanto o cenário Ano Normal representa a realidade da bacia nos dias atuais com baixo déficit hídrico, discriminando as regiões de maior e menor fragilidade em todo o território.

Para as condições de aumento de temperatura, todos os cenários analisados obtiveram aumento na fragilidade ambiental. Em circunstâncias otimistas, as regiões estudadas aumentaram sua fragilidade em $28 \%$. Regiões que antes não apresentavam situações graves de fragilidade, nos anos Seco e Normal, passam a apresentar alta fragilidade. Essas análises se demonstraram importantes para ressaltar as evidências de déficit hídrico no território e os prováveis problemas, caso as previsões do IPCC (2014) se confirmem.

Os pecuaristas familiares são vulneráveis a essas mudanças por não apresentarem estratégias de aumento de sua resiliência frente aos possíveis impactos ambientais originados do aumento de temperatura. Ao construir estratégias para um desenvolvimento sustentável, agentes públicos e atores sociais devem pensar em conjunto em alternativas para melhoria socioambiental dos territórios mais frágeis.

Por fim, a região central da sub-bacia Alto Camaquã deve ser a primeira a sofrer ações no intuito de incentivar a manutenção das famílias de produção pecuária e, portanto, voltadas para a preservação do Bioma Pampa e desse território.

\section{RECOMENDAÇÕES}

Como recomendações e reflexões para trabalhos futuros, propõem-se aqui duas ações que poderiam minimizar as vulnerabilidades do território deste estudo. Essas são pensadas no sentido de se trazer retorno para a região, a longo prazo, portanto devem ser integradas às ações das associações dos pecuaristas familiares do Alto Camaquã de revalorização de suas atividades agrícolas.

A primeira ação seria de incentivo ao Turismo Rural e a segunda de Pagamento por Serviços Ambientais (PSA). Essas alternativas seguem um pensamento ideológico de sustentabilidade ambiental que visam à preservação dos recursos naturais. Ao contrário, em uma estratégia mais neoliberal de produtividade a qualquer custo, poderíamos afirmar que o Alto Camaquã é insustentável.

Tanto o turismo rural quanto o PSA são estratégias que, segundo Barbosa (2012), dependeriam de um novo pacto entre os agricultores e a sociedade. Neste pacto, deve-se pensar em um novo modelo de produção centrado no desenvolvimento do território e, levando em conta as potencialidades da região, dar-se-ia maior importância para os cuidados 


\section{FRAGILIDADES AMBIENTAIS E VULNARABILIDADE DOS PECUARISTAS FAMILIARES FRENTE À DISPONIBILIDADE HÍDRICA DO ALTO CAMAQUÃ/RS}

com a paisagem, com a biodiversidade e com os recursos naturais.

Essas estratégias, além de aumentar os cuidados com o território do Alto-Camaquã, trariam aos pecuaristas familiares uma alternativa para que suas atividades econômicas e culturais fossem mantidas, a fim de evitar os processos, já conhecidos, de migração rural para as cidades já sobrelotadas e insustentáveis. Aliás, ações como essas devem se tornar políticas públicas para conservação e preservação desse ambiente.

Espera-se que esses resultados sejam utilizados pelos órgãos públicos competentes, no sentido de que os agentes tomadores de decisão tomem providências que minimizem os problemas enfrentados pelos pecuaristas familiares, em função de sua forte dependência dos recursos hídricos.

\section{REFERÊNCIAS BIBLIOGRÁFICAS}

CARDOSO, O. R. et al. Análise de fragilidade ambiental na bacia do rio Pardo - RS, frente à instalação de pequenas centrais hidrelétricas (PCHs). Porto Alegre, Revista Brasileira de Recursos Hídricos, v. 20, n. 2 p. 507-522, abr./jun. 2015.

CARVALHO NETO, R. M. Uso do Balanço Hídrico Climatológico para subsidiar tomadas de decisão quanto ao manejo de Bacias Hidrográficas. 2014. 90 p. Dissertação (Mestrado em Engenharia Civil) - Universidade Federal de Santa Maria. Santa Maria, 2014.

CARVALHO, C. M.; CRUZ, R. C. As representações sociais dos pecuaristas familiares do Alto Camaquã na construção de uma estratégia de desenvolvimento territorial. In: I Simpósio de Meio Ambiente da Universidade Federal do Pampa, Caçapava do Sul,2013.

CARVALHO, C. M.; NUNES, D. S.; ROCHA, N. S.; CRUZ, R. C. A construção da gestão e educação ambiental dos recursos hídricos na pecuária familiar do Alto Camaquã. Revista Monografias Ambientais, v.13, n.5, p.4019-4027, dez. 2014.
Avaliação da vulnerabilidade ao risco de contaminação dos recursos hídricos subterrâneos do município de Piratini-RS. Revista Monografias Ambientais, v. 13, n. 5, p. 3977-3985, 2014(a).

CARVALHO, C.M. A pecuária familiar e a gestão de recursos hídricos da bacia hidrográfica do Rio Camaquã: um estudo de caso no território do Alto Camaquã. 2015, 121p. Dissertação (Mestrado em Engenharia Ambiental). Universidade Federal de Santa Maria. Santa Maria, 2015.

CEREDA JUNIOR, A.; RÖHM, S. . Proposal and Analysis of Environmental Fragility Model Using Multicriteria Analysis And Fuzzy Logic For Integrated Landscape Mapping. Journal of Urban and Environmental Engineering (UFPB), v. 8, p. 28-37, 2014.

COLAVITE, A. P.; PASSOS, M. M. Integração de mapas de declividade e modelos digitais tridimensionais do relevo na análise da paisagem. Revista Geonorte. ed. especial, v.2, n.4, p. 15471559, 2012.

CRUZ, R. C.; GUADAGNIN, D. L. Uma pequena história ambiental do Pampa: proposta de uma abordagem baseada na relação entre perturbação e mudança. In: COSTA, B. P.; DIECKEL, M. E. G. (Org.). A sustentabilidade da Região da Campanha- RS: Práticas e teorias a respeito das relações entre ambiente, sociedade, cultura e políticas públicas. Santa Maria, RS: UFSM, PPG Geografia e Geociências, Dep. de Geociências, p. 155-179, 2010.

CRUZ, R. C. et al. Uma análise crítica dos conceitos de análise de fragilidades ambientais e de avaliação ambiental integrada. In: QUINTA-FERREIRA, M., BARATA, M. T.; LOPES, F.C.; ANDRADE, A. I.; HENRIQUES, M. H.; PENA DOS REIS, R.; IVO ALVES, E. (Org.). Para desenvolver a terra. Memórias e notícias de geociências no espaço lusófono. 1. ed. Coimbra: Imprensa da Universidade de Coimbra, v. 3, p. 18, 2012.

FEPAM. Fundação Estadual de Proteção Ambiental, SEMA, Secretaria Estadual de Meio 


\section{FRAGILIDADES AMBIENTAIS E VULNARABILIDADE DOS PECUARISTAS FAMILIARES FRENTE À DISPONIBILIDADE HÍDRICA DO ALTO CAMAQUÃ/RS}

Ambiente. Zoneamento Ambiental para atividade de silvicultura. v. I e II. Porto Alegre, Janeiro de 2007.

IBGE. Instituto Brasileiro de Geografia e Estatística. Dados do Censo Agropecuário,2006. Disponível em: http://www.ibge.gov.br. Acesso em 19 jan. 2015.

IPCC, Intergovernmental Panel on Climate Change. Cambios Climáticos 2014: Impactos, Adaptación y vulnerabilidad. Contribución del grupo de trabajo al quinto informe de evaluación del grupo intergubernamental de expertos sobre el cambio climático.34p. 2014.

MATTE, A. Vulnerabilidades, capacitações e meios de vida dos pecuaristas de corte da Campanha Meridional e Serra do Sudeste do Rio Grande do Sul. 2013, 176 f. (Dissertação de Mestrado em Desenvolvimento Rural) Universidade Federal do Rio Grande do Sul, Porto Alegre, 2013.

MMA. Ministério do Meio Ambiente. Interrelações entre biodiversidade e mudanças climáticas. Brasília: PROBIO/MMA, 2007. 221 p.

Projeto Relatório 1 - Desenvolvimento metodológico e tecnológico para avaliação ambiental integrada aplicada ao processo de análise de viabilidade de hidrelétricas. Santa Maria: UNIPAMPA/UFSM, 2009.

Projeto Relatório 2 - Desenvolvimento metodológico e tecnológico para avaliação ambiental integrada aplicada ao processo de análise de viabilidade de hidrelétricas. Santa Maria: UNIPAMPA/UFSM, 20011.

NESKE, M. Z.; Andrade, M.L.; BORBA, M. F. S. Capital Ecológico e a Construção de Autonomia na Produção Familiar: o caso da pecuária familiar do Rio Grande do Sul. Cadernos de Ciência \& Tecnologia, v. 29, p. 291-317, 2012.

NESKE, M. Z. Estilos de agricultura e dinâmicas locais de desenvolvimento rural: o caso da pecuária familiar no território do Alto Camaquã do Rio Grande do Sul. 2009. 208 p. Dissertação
(Mestrado em Desenvolvimento Rural). Universidade Federal do Rio Grande do Sul. Porto Alegre, 2009.

NESKE, M. Z.; MARQUES, F. C.; BORBA, M. F. S. A emergência da produção de novidades em territórios marginalizados: uma análise a partir do território Alto Camaquã, Rio Grande do Sul. Desenvolvimento e Meio Ambiente (UFPR), v. 31, p. 43-59, 2014.

NOBRE et al. Riscos de mudanças climáticas no Brasil e limites à adaptação. 2016. Embaixada do Reino Unido no Brasil.

PADILHA, D. G. Geoprocessamento aplicado na caracterização da fragilidade ambiental da Bacia hidrográfica do Arroio Grande, RS. Dissertação (Mestrado em Geomática). Universidade Federal de Santa Maria, 2008.

Modelo de apoio à decisão aplicado ao planejamento territorial de silvicultura baseado em análise multicritério de redes neurais artificiais. 2014. p 287. Tese (Doutorado em Engenharia Florestal). Universidade Federal de Santa Maria. Centro de Ciências Rurais. Santa Maria, 2014.

PADILHA, D. G.; TREVISAN, M. L.; CRUZ, J. C. Sensibilidade do modelo de fragilidades ambientais à ponderação multicriterial. Floresta (Online). Curitiba, v. 44, p. 535-458, 2014.

PLOEG, J. D. V. D. Camponeses e Impérios Alimentares: lutas por autonomia e sustentabilidade na era da globalização. Tradução de Rita Pereira. Porto Alegre: Editora da UFRGS, 2008. 372 p.

ROBOREDO, D.; BERGAMASCO, S.M.P.P.; BLEICH, M.E. Aggregate index of social- environmental sustainability to evaluatethe socialenvironmental quality in a watershed in the Southern Amazon. Ecological Indicators, v. 63. p.337-345, 2016.

ROCHA, J. M.; CRUZ, R. C.; ZANELLA, F. C.; ROCHA, N. S. Uso do geoprocessamento para análise temporal de uso da terra no Assentamento São 
ROCHA, N. S., CRUZ, R. C., PADILHA, D. C., CARVALHO, C. M.

\section{FRAGILIDADES AMBIENTAIS E VULNARABILIDADE DOS PECUARISTAS FAMILIARES FRENTE À DISPONIBILIDADE HÍDRICA DO ALTO CAMAQUÃ/RS}

Joaquim. In: 4ㅇSeminário Brasileiro de Gestão Ambiental na Agropecuária, 2014, Bento Gonçalves. Anais... v. 4, p. 158-163,2014.

ROCHA, J. M. As raízes da crise da Metade Sul: estudo da formação econômica do Rio Grande do Sul. 1. ed. Bagé: Fundação Universidade Federal do Pampa, 2011.

ROCHA, N.S. Efeitos do aumento da temperatura sobre a disponibilidade hídrica para a pecuária familiar na sub-bacia do Alto Camaquã, RS. 2016, 197p. Dissertação (Mestrado em
Engenharia Ambiental). Universidade Federal de Santa Maria. Santa Maria, 2016.

SANTOS, R. F. Planejamento ambiental: teoria e prática. São Paulo. Oficina de Textos. 2004. 184 p.

TREVISAN, M. L. Sensibilidade de fatores para valoração do ambiente com o uso de avaliação multicritério e geoprocessamento digital. $165 \mathrm{f}$. Tese (Doutorado em Engenharia Agrícola) Universidade Federal de Santa Maria, Santa Maria,

2008. 